\title{
TREATMENT SEEKING BEHAVIOUR FOR PULMONARY TUBERCULOSIS AMONG CHEST SYMPTOMATICS IN BHUTAN
}

\section{Laygoi M}

Royal Institute of Health Sciences, Thimphu, Bhutan

\begin{abstract}
Introduction: TB is one of the sixth leading diseases that cause deaths in Bhutan. There were 1344 new cases in 1989 and 1060 cases in 1992. About 910 people develop tuberculosis every year. Observing the increasing trend, this study was conducted in community and in hospitals from January 2006 to June 2007 in Bhutan. The overall objective of this study is to identify the factors influencing delays in seeking health care for tuberculosis among TB patients and TB suspects.
\end{abstract}

Methodology: The study was conducted in the community and hospital from January 2006 to June 2007 among 200 TB patients and 200 TB suspects with 5 TB patients and 5 TB suspects in depth focus group interviews with 10 groups of health workers and 10 groups of community people. Two groups of people were taken; one group had active tuberculosis and another group who were TB suspects. Moreover, health worker and community people were also asked about the disease. Two methodologies were used, one was structured questionnaires and another was in-depth and focus group interviews.

Results: TB patients' delay ranged from $0-210$ days and median delay was 17.5 days. Patient's delay in TB suspects ranged from 0 to 365 days with median delay of 14 days. "Covering mouth" while talking, was the most common stigma that came out of the interviews.

Conclusion: The study brought out certain important factors like; the increasing trend of disease may be due to the fact that people delay in seeking treatment.

Key words: TB, Delay, Patients, Seeking, Treatment.

\section{INTRODUCTION}

Global trend shows that tuberculosis is still a major problem among the developing countries which is true in case of Bhutan also. DOTS treatment is available in all district hospitals; though the number of cases is not diminishing. Therefore, this study was taken to explore the factors influencing delay in health seeking and social stigma perceived by TB patients and TB suspects.

Tuberculosis is one of the most challenging diseases prevalent in Bhutan and existed from the earliest time in history of Bhutan. ${ }^{1} \mathrm{~A}$ detailed

\section{Correspondence:}

Manikala Laygoi

Royal Institute of Health Sciences,

Thimphu, Bhutan analysis of situation about the TB disease was carried out in the end of 1993 and decision was taken to implement short course chemotherapy in 1994. ${ }^{1}$ The Ministry of Health established National Tuberculosis Control Program to achieve $80 \%$ case detection and have 100\% BCG coverage, with nationwide short course therapy (TB manual, 2005). There were 1344 new cases in 1989 and in 1992 there were 1060 case reported (AHB, 1989-92). About 910 people estimated to develop tuberculosis every year in Bhutan. ${ }^{2}$ To contain and manage TB, Ministry of Health initiated regulated control programs since 1994. It still remains a challenge. In 2005, total new and retreated cases were 1018, new cases were 310 . Mortality rate due to TB is $29(4.12 \%)$ in 2005 along with other diseases. $^{3}$

The main strategy of NTCP in Bhutan is to achieve $100 \%$ DOTS treatment coverage, reduce 
prevalence to 1 per 1000 population (TB control manual, 2001) and create awareness among people about TB, enabling early diagnosis and treatment. Hospitals keep smear positive cases in isolation and patients are sent home once sputum negative.

Basic Health Units lack the facility to diagnose and treat tuberculosis though health assistant prepare sputum slides for suspected cases and send them to district hospitals for diagnosis. Health staff collects anti-tuberculosis drugs from district hospitals for patients who cannot collect themselves.

According to $\mathrm{WHO}^{4}$ out of the seven million people living with HIVIAIDS in the Region, over half are infected with TB. Of these nearly 150,000 newly diagnosed TB patients, are estimated to be resistant to first-line anti-TB drugs. With $25 \%$ of the world's population, the South East Region is home to the largest numbers of TB patients in the world.

In Bhutan, at present there are 1150 cases of all types of TB. In 2007 there were 328 sputum positive cases and in 2008 there are 351. In addition, there are 11 TB-HIV co-infection cases. There was no study done before to know why people are contracting the disease in spite of free availability of the DOTS, anti-TB drugs, furthermore in Bhutan people do have lots of local beliefs that may hamper people for not seeking treatment in time. No explorative study is done to find out the cause of increasing trend in-spite of having free drugs availability and high awareness campaigns.

The overall objective of this study is to identify the factors influencing delays in seeking health care for tuberculosis among TB patients and TB suspects. In addition, barriers to seeking health care for respiratory symptoms in the general population were explored. Specific objectives were to determine the interval between the onset of respiratory symptoms and TB diagnosis for both TB patients and TB suspects.

1. To evaluate social stigma as a factor for delayed seeking.

2. To describe and compare the factors influencing delays in health seeking behaviour.

3. To explore and identify some of the potential reasons for delayed care among chest symptomatics.

\section{METHODOLOGY}

\section{Sample, sample size and study period}

This study adopted both quantitative as well as qualitative design. It is cross-sectional study done in ten hospitals who reported highest TB cases. As the number of cases coming to hospital was less, non probability sampling using purposive sampling was adopted to administer questionnaires. The patients who were newly diagnosed TB were taken at that point of time from ten hospitals. In-depth interview and focus group interviews were used in qualitative design.

Study I- Structured questionnaires were administered to 200 newly diagnosed (within two weeks) TB and 200 chest symtomatics patients. Patients included both sexes. Study was done over a period of one and half year.

Study II- 5 newly diagnosed TB patients and 5 TB suspects who do not seek diagnosis and treatment. 10 -focus group interviews with different category of health workers including both sexes and 10Focus group interviews with community members

\section{Data collection}

After the questionnaires were tested by panel of experts from World Health organization, the focal persons were trained to use questionnaires and undertake in depth interviews. The questionnaires and the tapes were sent to ten hospitals through these focal persons. As the questionnaires were filled, interviews were recorded; the focal person brought them to principal investigator. The data was jointly collected by principal investigator, health workers, nurses who were trained to administer questionnaires and conduct in-depth interviews. The focus group discussion was conducted by the principal investigator in all places. Triangulation of data enhanced credibility of data and converse for the truth. ${ }^{5}$

\section{Ethical consideration}

The permission was sought from the Ministry of Health through Health Research Working Committee. In each district, the District Medical Officer's permission was taken to conduct the 
study. Additionally, informed consent from patients and TB suspects was taken to conduct interviews. Relapsed cases, below 18 years of age \& those who refused to take part in the study were excluded from study.

\section{Data analysis}

The questionnaires was analysed using Epi-Info and simple statistics and advanced statistics e.g. complex sample means, liner and logistic regression. The $P$ value was set at was 0.05 . The analysis is displayed using table and bar graph. SPSS was used for simple and advanced descriptive statistics. As personal and group interview are less formulaic, mostly is to organise, provide structure and elicit meaning from data. Investigator triangulation, a tool that enhances trustworthiness and the tape and field notes were read and reread then integrated and interpreted. Content analysis aids to identify prominent themes and identify patterns among the themes. Comprehending and synthesizing paradigms was done after listening to tapes repeatedly and filling gaps through field notes and transcription of data followed coding and extraction of themes. Plethora of data assisted to take consensus and agree on the themes. From the three categorical style of qualitative analysis, editing analysis was somewhat applicable. This style adopts developing of category schemes and gives corresponding codes that helps to sort and organise data. This style somewhat fit to analyse transcript of ten groups of focus group discussion and ten in-depth interviews. Taking of views of community people, health worker and patient did capture insightful construct thus finding are meaningful to be applied. For this method, representative sample and data saturation were the guiding principle. ${ }^{5}$

Study I- Being a cross sectional descriptive study, all patients present at the time of administering questionnaire were taken. The basis of selection was that the interviewer waited till patient was confirmed TB positive. The admitted patients were administered structured questionnaires. This process went on every time a new patient was admitted. Some patients were interviewed by the TB unit In-charge. Patients who are not admitted in wards are referred to the TB Unit for registration and collect medicine. Those newly diagnosed patients were administered questionnaires. Any patient who did not registered for the medicine may be missed but hardly TB patients' buys medicine on their own as medicine is freely available in all hospitals. All patients who were approached by the interviewer did agree to be the participants. The characteristics of patients are shown in graphs and attached as appendix. For chest symptoms, similar process was adopted till the specified number of patients were completed.

Study II- An in-depth interview was held with a sample size of 5 TB patients who are discharged after being sputum negative. Each subject was from different district. Another in-depth interview was carried out with 5 community members with respiratory symptoms who did not seek care. They were evaluated using in-depth interviews; each one was from different district hospital. Focus group discussion was carried out with ten groups of health worker consisting of mixed people e.g. nurses, technician, doctors, specialist, health assistant, basic health worker and auxiliary nurse midwife. The group had both sexes. The focus group discussion was done in ten Districts. The focus group discussions were also carried out with eight groups of community members having both male and females. Each focus group discussion was carried out in different Districts, a total of ten districts were selected. Almost all approached patients agreed to be the participants.

The most significant risk factor was losing the job. People who were working in hotels and as maids did not want to reveal the disease to their employees for fear of losing their jobs. The next was fear of getting separated from spouse therefore the disease was revealed to the parents only.

\section{RESULTS}

The mean number of days in delay of TB patients \& suspects were $30.10 \& 64.86$, respectively. The commonest stigma was "covering mouth" while talking (Table 1). The mean age of male \& female participants were $48.56 \& 42.47$, respectively (Table 2). Most TB patients visiting the hospital were from Tashigang district (Figure 1). 
Table 1. Correlations between Delay and Stigmas for TB Patients

\begin{tabular}{|l|l|r|r|r|r|r|r|r|r|r|r|r|r|}
\hline & & DELAY & \multicolumn{1}{|c|}{ N1I } & \multicolumn{1}{c|}{ N1II } & \multicolumn{1}{c|}{ N1III } & \multicolumn{1}{c|}{ N1IV } & N1V & N1VI & N1VII & N1VIII & N1IX & N1X & N1XI \\
\hline DELAY & $\begin{array}{l}\text { Pearson } \\
\text { Correlation }\end{array}$ & 1 & .063 & $.160\left(^{*}\right)$ & -.070 & .007 & .052 & .141 & .065 & .085 & .032 & -.095 & $.195\left(^{* *}\right)$ \\
\hline & $\mathrm{N}$ & 200 & 179 & 182 & 184 & 181 & 179 & 184 & 182 & 185 & 182 & 175 & 178 \\
\hline
\end{tabular}

* Correlation is significant at the 0.05 level (2-tailed), ${ }^{* *}$ Correlation is significant at the 0.01 level (2-tailed)N1l; People doesn't call in social events, N1II; Get kicked out of work, N1III; Friends avoid them, N1IV; Avoid marriage, N1V; People served in broken utensils, N1VI; Covers mouth while talking, N1VII; Friends do not shake hands, N1VIII; People avoid TB patients, N1IX; Patients avoid treatment due to fear of exposure, N1X; Discrimination is less if sputum is negative, N1XI; Spouse deserts you

\begin{tabular}{|c|c|c|c|c|c|}
\hline \multicolumn{6}{|c|}{$\begin{array}{l}\text { Table 2. Complex Samples of Means of Age and } \\
\text { Sex }\end{array}$} \\
\hline \multirow{2}{*}{ S. No. } & \multirow{2}{*}{ Sex } & \multirow{2}{*}{ Count } & \multirow{2}{*}{$\begin{array}{l}\text { Mean } \\
\text { (age) }\end{array}$} & \multicolumn{2}{|c|}{$\begin{array}{c}\text { Confidence } \\
\text { Limits(age) } 95 \% \\
\end{array}$} \\
\hline & & & & Lower & Upper \\
\hline 1 & $M$ & 107 & 48.56 & 28.91 & 68.21 \\
\hline 2 & $\mathrm{~F}$ & 93 & 42.47 & 20.90 & 64.04 \\
\hline TOTAL & & 200 & 45.73 & 25.93 & 65.52 \\
\hline
\end{tabular}

Name of Districts of Bhutan
1. Samtse,
11. Trongsa
2. Chukka,
12. Wangdiphodrang
3. Dagana,
13. Punakha
4. Damphu,
14. Thimphu
5. Sarpang,
15. Paro
6. Zhemgang,
16. Jakar
7. Mongar,
17. Lhuntse
8. Pemagatshel,
18. $\mathrm{Ha}$
9. Samdrup Jongkhar,
10. Tashigang
19. Yang-Tse
20. Ga.

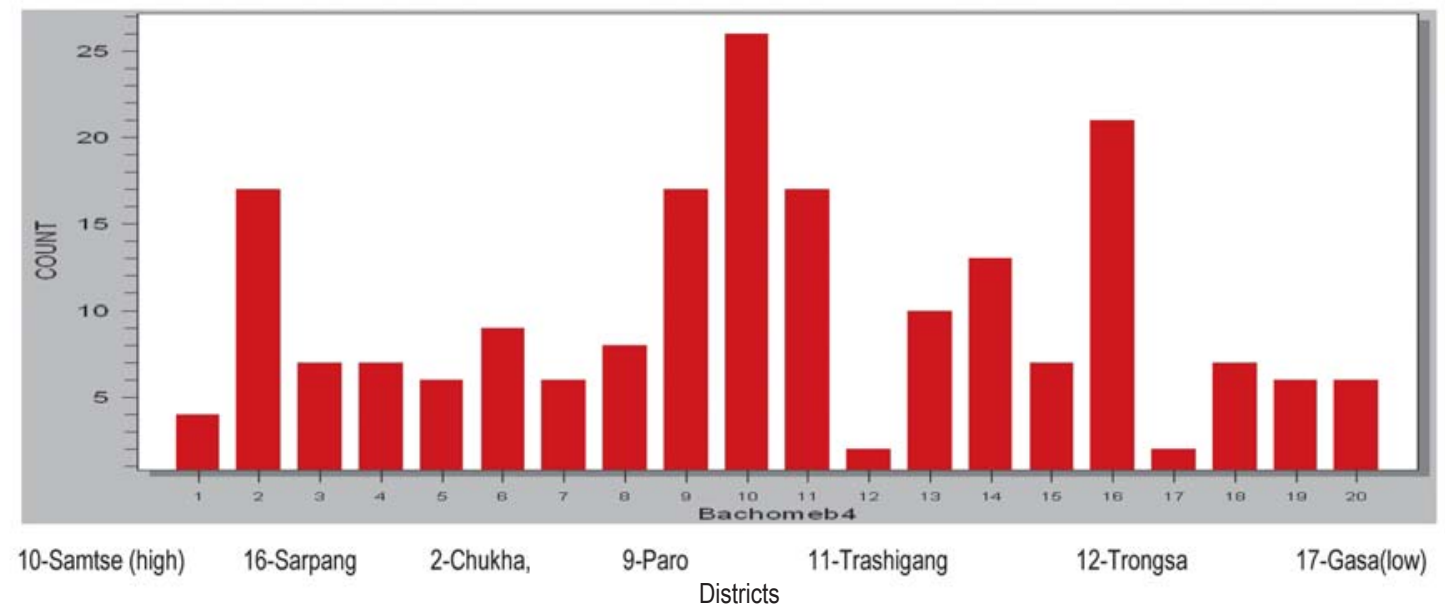

Figure 1. Number of patients from 20 districts

\section{DISCUSSION}

People delayed for diagnosis and treatment from few days to one week. For in-depth interview, the delay was one week that was mentioned by almost every interviewee. Conducting of religious ritual and performance by local healer before taking patients to health facility was mentioned by many patients as people go to local healer before bringing patients to health facility. High incidence of acute respiratory infection does mask the TB symptoms as in every health facility, ARI tops the ten most priority disease therefore TB may be mistaken as ARI and not treated properly. The delay within the health facility to diagnose and treat patient was another point noted during the in-depth interview, where from seeing a physician, getting investigated, diagnose to treatment takes one week in hospitals.

In this regard the educating of religious people has become very vital. If people fall sick, the religious ritual and the visit to health facility should be done side by side and not only do religious rituals. But few local healers do advice against visiting health facility. The behaviour of people regarding the delay due to religious ritual can be addressed through IEC activities. 
The other forms of delay due to health worker and the health facility may be solved through equipping the facility with manpower and equipments. People are aware of symptoms of TB but they fail to put together these symptoms and suspect TB. Among the symptoms, haemoptysis was considered as highest priority and people diagnose it as TB. The incidence of TB was higher in southern Bhutan and less in northern Districts e.g. Gasa and Trongsa (Figure 1) almost every person visited health facility for treating respiratory symptoms once a year only. Among chest symptomatic, there are people who were chronically suffering from some sort of chest symptoms, therefore some people have said that they have suffered for several years. Most of the stigmas were pointed out by clients from Southern Bhutan and people from Northern side did not discriminate TB patient that much. Understanding the help seeking behaviour of the people towards the disease it is important to plan appropriate measures in controlling TB. Eradication of the disease itself will take a concerted effort on the partof the health workers, doctors, researchers, patients, and the program unit. TB Program is escalating IEC activities to create awareness among people and thereby bring down both morbidity and mortality rate of the country. As mentioned above, a study with larger sample would give a true view of TB situation in Bhutan. This study was a challenge that taught and used health workers, nurses, patients, relatives to be more aware about TB. Along with interviews, patients were encouraged to ask any misgivings on TB. Guidance and health education for adherence to drug till full course is completed and information on taking rest and balanced diet during the convalescence were conveyed.

\section{CONCLUSION}

The study brought out certain important factors that were; the increasing trend of disease may be due to the fact that people delay in seeking treatment. They first visit the local healer and later on then only come to hospitals. The symptoms on coughing are taken as only acute respiratory infection and not relate to TB unless the patient has hemoptysis. this view was same with the health worker, community people and relatives. Another fact was in people knew that one has TB, the patient was barred from visiting people's house during religious ceremonies and also may be out of the employment. People were aware of the drugs availability in hospitals.

\section{REFERENCES}

1. Namgyal P. Guidelines for National TB control program TB control Manual Department of Health, Bhutan. 1994

2. Guidelines for National TB control program., TB Control Manual Public Health Department, Bhutan 2001.

3. Annual health Bulletin $(2006,2008,2009)$ Ministry of Health. Thimphu, Bhutan.

4. Communicable Diseases, Tuberculosis, Factsheet. Downloaded on March 2007. http://www.who.int/ mediacentre/factsheets/en/.Fact sheet No 104. (Cited 2006 April 27).

5. Polit D, Beck F. Essentials of Nursing Research, method, appraisal \& utilization. $6^{\text {th }}$ ed. Lippincott William \& Wilknis 2006. 